\title{
GCU
}

Glasgow Caledonian

University

University for the Common Good

\section{Treatment of selected pharmaceuticals by ferrate(VI): Performance, kinetic studies and identification of oxidation products}

Zhou, Zhengwei; Jiang, Jia-Qian

Published in:

Journal of Pharmaceutical and Biomedical Analysis

DOI:

10.1016/j.jpba.2014.06.032

Publication date:

2015

Document Version

Author accepted manuscript

Link to publication in ResearchOnline

Citation for published version (Harvard):

Zhou, Z \& Jiang, J-Q 2015, 'Treatment of selected pharmaceuticals by ferrate(VI): Performance, kinetic studies and identification of oxidation products', Journal of Pharmaceutical and Biomedical Analysis, vol. 106, pp. 37-45. https://doi.org/10.1016/j.jpba.2014.06.032

\section{General rights}

Copyright and moral rights for the publications made accessible in the public portal are retained by the authors and/or other copyright owners and it is a condition of accessing publications that users recognise and abide by the legal requirements associated with these rights.

Take down policy

If you believe that this document breaches copyright please view our takedown policy at https://edshare.gcu.ac.uk/id/eprint/5179 for details of how to contact us. 


\title{
Treatment of selected pharmaceuticals by ferrate(VI): Performance, kinetic studies and identification of oxidation products
}

Zhengwei Zhou, Jia-Qian Jiang*

School of Engineering and Built Environment, Glasgow Caledonian University, Glasgow G4 0BA, Scotland, United Kingdom

* Corresponding author: J-Q Jiang, Tel.: +44 141331 8850; E-mail address: jiaqian.jiang@gcu.ac.uk

\begin{abstract}
The performance of ferrate(VI) in treating sulfamethoxazole (SMX), diclofenac (DCF), carbamazepine (CBZ) and bezafibrate (BZF) in test solutions containing the four compounds was investigated. A series of jar-test experiments was performed on a bench-scale at $\mathrm{pH}$ 6-9 and at a ferrate(VI) dose of 1-5 mg Fe/L. The results suggested that ferrate(VI) can effectively remove SMX, DCF and CBZ from the test solutions, with greater than $80 \%$ removal under optimum conditions. However, the removal efficiency of BZF was very low, less than $25 \%$ under the studied conditions. Increasing the dose of ferrate(VI) improved the treatment performance, while the influence of solution $\mathrm{pH}$ on ferrate(VI) performance varied among the different target compounds. Ferrate(VI) demonstrated the highest reactivity with SMX at $\mathrm{pH} 8$ and $\mathrm{pH} 9\left(20{ }^{\circ} \mathrm{C}\right)$, with apparent second-order rate constants of $360 \pm 17 \mathrm{M}^{-1}$ $\mathrm{s}^{-1}$ and $1.26 \pm 0.02 \mathrm{M}^{-1} \mathrm{~s}^{-1}$, respectively. However, BZF showed the lowest removal by ferrate(VI) with the smallest rate constants (less than $0.5 \mathrm{M}^{-1} \mathrm{~s}^{-1}$ ) at $\mathrm{pH} 8$ and $\mathrm{pH} 9$. Furthermore, a number of oxidation products (OPs) of SMX, DCF and CBZ during ferrate(VI) oxidation were detected by liquid chromatography and mass spectrometry (LC-MS), and their degradation pathways were tentatively proposed. No OPs of BZF were detected during ferrate(VI) oxidation.
\end{abstract}

Keywords: Ferrate(VI), Oxidation productions (OP), Pharmaceuticals, Rate constants 


\section{Introduction}

The detection of a great variety of pharmaceuticals at trace levels $(\mathrm{ng} / \mathrm{L}-\mu \mathrm{g} / \mathrm{L})$ in the aquatic environment has led to increasing public concern [1-3]. The long-term effects of these trace pharmaceutical residues on human beings and the eco-system are still not clear. Nevertheless, worries of potential adverse effects remain $[4,5]$. Therefore, studies investigating the removal of the pharmaceuticals from water and wastewater have been carried out recently $[6,7]$, mainly focusing on ozonation and advanced oxidation processes (AOPs). Ozone, as a selective oxidant, tends to have great capability in oxidising pharmaceuticals containing electron-rich moieties (ERMs) (e.g. sulfamethoxazole) rather than those without ERMs (e.g. ibuprofen) $[8,9]$. On the other hand, hydroxyl radicals based AOPs have remarkable capability to degrade nearly all target pollutants with very high rate constants (up to $10^{9} \mathrm{M}^{-1} \mathrm{~s}^{-1}$ ) [10] while their applications in natural and wastewater treatment still face several challenges such like co-existing compounds (e.g. NOMs) and radical scavengers (e.g. $\mathrm{CO}_{3}{ }^{2-}$ and $\left.\mathrm{HCO}_{3}{ }^{-}\right)[11,12]$.

Ferrate(VI) salt is a promising dual-functional chemical for water and wastewater treatment and can achieve the reduction of a wide range of organic and inorganic pollutants in wastewater [13-15]. Moreover, unlike ozonation, ferrate(VI) does not generate bromate, a potentially carcinogenic by-product, in treating bromidecontaining waters [16]. Several studies examining the decontamination of pharmaceuticals in test solutions and pharmaceutical-spiked wastewater effluents by ferrate(VI) have been published [17-21]. The results demonstrated that ferrate(VI) possessed a great capability in treating pharmaceutical compounds with ERMs, e.g. ciprofloxacin, with removal efficiencies higher than $85 \%$. The second-order rate constants between ferrate(VI) and some pharmaceuticals were also determined (e.g. higher than $10^{3} \mathrm{M}^{-1} \mathrm{~s}^{-1}$ for sulfamethoxazole and triclosan). However, little information is available with regard to the optimisation of ferrate(VI) treatment for future practical application, such as the influence of the solution $\mathrm{pH}$ and the ferrate(VI) dosage. Furthermore, even though oxidation products (OP) and degradation pathways for the oxidation of several pharmaceuticals by ferrate(VI) have been proposed [22, 
23], a data-base containing similar information on many other pharmaceuticals needs to be established.

In this study, ferrate(VI)'s performance and degradation pathways in treating selected pharmaceuticals were investigated. The target compounds chosen for the experiments were sulfamethoxazole (SMX), diclofenac (DCF), carbamazepine (CBZ) and bezafibrate (BZF), and their basic properties are presented in Table S1 of the Supplementary Material (SM). These compounds belong to different therapeutic groups, namely antibiotics (SMX), antiphlogistics (DCF), antiepileptics (CBZ) and lipid regulators (BZF), and have been found widely in the aquatic environment with concentrations up to hundreds of ng/L $[24,25]$. The objectives of this study were 1) to investigate the influence of solution $\mathrm{pH}$ and ferrate(VI) dosage on the removal of the selected pharmaceuticals; 2) to determine the rate constants of the reaction of ferrate(VI) with target compounds; and 3) to identify OPs and propose degradation pathways of four target pharmaceuticals during ferrate(VI) oxidation. To our best knowledge, this is the first study to investigate the removal of BZF by ferrate(VI) and identify the OPs of DCF during ferrate(VI) treatment.

\section{Materials and methods}

\subsection{Chemicals and reagents}

Sulfamethoxazole (SMX), diclofenac sodium (DCF), carbamazepine (CBZ) and bezafibrate (BZF) of analytical grade or above were purchased from Sigma-Aldrich (UK). Potassium ferrate(VI) (purity higher than 90\%) was also obtained from SigmaAldrich (UK). Other chemicals and solvents were supplied by Fisher Scientific (UK). All chemicals and solvents were used without further purification. Experimental water was generated by an Elga PureLab Option-R 7/15 pure water system (Veolia Water, France). Stock solutions of ferrate(VI) were freshly prepared by dissolving solid $\mathrm{K}_{2} \mathrm{FeO}_{4}$ in $0.0125 \mathrm{M} \mathrm{Na}_{2} \mathrm{~B}_{4} \mathrm{O}_{7} \cdot 10 \mathrm{H}_{2} \mathrm{O} / 0.005 \mathrm{M} \mathrm{HCl}$ buffer solution at $\mathrm{pH} 9.0$ to make a ferrate(VI) concentration of $1 \mathrm{~g} / \mathrm{L}$ as Fe.

Two approaches were utilised to prepare stock solutions of target pharmaceuticals 
for different purposes. (1) Jar test experiments and identification of OPs: stock solutions of target compounds were prepared in methanol at $100 \mathrm{mg} / \mathrm{L}$. (2) Kinetic studies: stock solutions of DCF and SMX, which have high aqueous solubility (higher than $500 \mathrm{mg} / \mathrm{L}$ at experimental temperature), were prepared by directly dissolving solid chemicals in pure water. On the other hand, stock solutions of CBZ and BZF were prepared in acetonitrile at the appropriate concentrations to yield a $2 \%(\mathrm{v} / \mathrm{v})$ percentage of acetonitrile in the final diluted test solutions. It has been reported that $2 \%$ acetonitrile in solution exerts little influence on reactions with ferrate(VI) [26].

\subsection{Jar test experiments}

Test solutions (one litre each) with two levels of concentrations for each compound, 100 and $10 \mu \mathrm{g} / \mathrm{L}$, were prepared in buffer solutions at $\mathrm{pH} 6-9$, the $\mathrm{pH}$ range that is usually applied in practical water and wastewater treatment. The buffer solutions employed were $0.05 \mathrm{M} \mathrm{KH}_{2} \mathrm{PO}_{4} / 0.005-0.05 \mathrm{M} \mathrm{NaOH}$ for $\mathrm{pH}$ 6-8 and $0.0125 \mathrm{M} \mathrm{Na}_{2} \mathrm{~B}_{4} \mathrm{O}_{7} \cdot 10 \mathrm{H}_{2} \mathrm{O} / 0.005 \mathrm{M} \mathrm{HCl}$ for $\mathrm{pH} 9$.

A series of jar test experiments was carried out with a six-unit stirrer (Kemira flocculator 2000, Kemwater) under the following protocol: fast mixing for $1 \mathrm{~min}$ at $400 \mathrm{rpm}$; slow mixing for $60-180 \mathrm{~min}$ at $40 \mathrm{rpm}$; and then sedimentation for $60 \mathrm{~min}$. The ferrate(VI) dose applied was $0-5 \mathrm{mg} / \mathrm{L}$ as Fe. All experiments were conducted in duplicate.

A specified amount of the supernatant was filtered sequentially with $1.2 \mu \mathrm{m}$ glass fibre filters (Fisher Scientific, UK) and $0.45 \mu \mathrm{m}$ membrane filters (Millipore, USA) after sedimentation. The solution $\mathrm{pH}$ of the filtrate was adjusted to 2.5 by $1 \mathrm{M} \mathrm{H}_{2} \mathrm{SO}_{4}$ and then subjected to solid phase extraction (SPE) and further analysis by high performance liquid chromatography (HPLC)-UV.

\subsection{Kinetic studies}

Kinetic studies of ferrate(VI) with the target compounds were performed with the pharmaceuticals in excess (pseudo-first-order condition). The room temperature was $20 \pm 2{ }^{\circ} \mathrm{C}$ throughout the kinetic studies. A low ferrate(VI) dosage $(2.5-10 \mu \mathrm{M})$ was applied to lower the self-decomposition rate of ferrate(VI). The rate constants were 
determined at $\mathrm{pH} 8$ and $\mathrm{pH}$ 9. The reaction was started by dosing ferrate(VI) solution into $500 \mathrm{~mL}$ buffered test solutions under stirring at $200 \mathrm{rpm}$. Aliquots of the reacting solution were then quenched with ABTS solution at certain time intervals. The remaining ferrate(VI) was measured by the ABTS method at $415 \mathrm{~nm}$ [27] using a DR3900 VIS spectrophotometer (Hach-Lange, USA). For the details of the ABTS method, please see Text S1 of the SM. The kinetic experiments were performed in triplicate for each condition.

\subsection{Identification of oxidation products}

Test solutions containing $10 \mathrm{mg} / \mathrm{L}$ of the target compounds were prepared separately in pure water. Two levels of ferrate(VI) doses $(5 \mathrm{mg} / \mathrm{L}$ and $10 \mathrm{mg} / \mathrm{L}$ as $\mathrm{Fe})$ were applied to the stirred test solutions at $200 \mathrm{rpm}$ to investigate whether the higher dose $(10 \mathrm{mg} / \mathrm{L})$ would improve the formation of OPs. The solution $\mathrm{pH}$ was carefully adjusted by $0.01 \mathrm{M} \mathrm{H}_{2} \mathrm{SO}_{4}$ or $0.02 \mathrm{M} \mathrm{NaOH}$ to yield a final $\mathrm{pH}$ of 6.5-7.5. A selected portion of the solution was filtered by $0.45 \mu \mathrm{m}$ Puradisc syringe filters (Whatman, USA) after the reaction was completed. Then, the solution $\mathrm{pH}$ was adjusted to 2.5 using $1 \mathrm{M} \mathrm{H}_{2} \mathrm{SO}_{4}$ for further liquid chromatography (LC)-mass spectrometry (MS) analysis. The experiments were operated in parallel under identical conditions.

\subsection{Analytical methods}

The remaining pharmaceutical compounds present in the treated test solutions were enriched by solid phase extraction (SPE). The SPE cartridges employed were Strata-X $1 \mathrm{~g} / 12 \mathrm{~mL}$ giga tubes (Phenomenex, UK). Generally, the extraction method consisted of the following steps: (1) condition: $6 \mathrm{~mL}$ methanol; (2) equilibrate: $6 \mathrm{~mL}$ water; (3) load samples: flow desired amount of water samples under vacuum at a flow rate of 5-10 mL/min; (4) wash: $2 \times 6 \mathrm{~mL}$ water; (5) dry: 15 min under gentle nitrogen flow; and (6) elute: $2 \times 6 \mathrm{~mL} 2: 49: 49 \quad(\mathrm{v} / \mathrm{v} / \mathrm{v})$ formic acid/methanol/acetonitrile. The eluents were evaporated to dryness at $50{ }^{\circ} \mathrm{C}$ using a DB-2A Dri-Block (Techne, UK) and then re-constituted to $1 \mathrm{~mL}$ by 50:50 (v/v) methanol/water. The final enriched samples were filtered with $0.45 \mu \mathrm{m}$ Puradisc syringe filters (Whatman, USA) and subjected to HPLC analysis. 
An Agilent 1100 system (Agilent Technologies, USA) with a diode array detector (DAD) was employed for the measurement of target compounds. The column utilised for the separation of compounds was a $2.6 \mu \mathrm{m}, 100 \mathrm{~mm} \times 2.10 \mathrm{~mm}$ reversed phase Kinetex $\mathrm{XB}^{-\mathrm{C}_{18}}$ column (Phenomenex, UK). The column was kept at $25{ }^{\circ} \mathrm{C}$ and eluted by acetonitrile (Solvent A) and $0.1 \%$ formic acid in pure water (Solvent B) at a flow rate of $0.2 \mathrm{~mL} / \mathrm{min}$. The elution was initiated with $20 \%$ solvent $\mathrm{A}$. Then, the percentage of solvent A was increased to $45 \%$ over the next 6 min, held at this percentage for $15 \mathrm{~min}$ and finally lowered to $20 \%$ in $1 \mathrm{~min}$. The DAD wavelengths for BZF, SMX, DCF and CBZ detection were pre-determined and set at $230 \mathrm{~nm}, 270$ $\mathrm{nm}, 280 \mathrm{~nm}$ and $290 \mathrm{~nm}$, respectively. The method was validated and has been published elsewhere [28].

An Agilent 1100 HPLC plus a Bruker Daltonics Esquire 3000 ion trap mass spectrometer (MS) were employed to identify the OPs of target compounds treated by ferrate(VI). The separation was achieved by an Atlantis $\mathrm{C}_{18}$ column $(3 \mu \mathrm{m}, 150 \mathrm{~mm} \times$ $2.1 \mathrm{~mm}$, Waters, USA) using a gradient of acetonitrile (Solvent A)/ ammonium formate and formic acid in water ( $\mathrm{pH} 3.5$, Solvent B) at $0.2 \mathrm{~mL} / \mathrm{min}$. Solvent A was initially $1 \%$ and was maintained at this percentage for $2 \mathrm{~min}$. Then, the percentage was increased to $30 \%$ in the next $1 \mathrm{~min}$ and stayed at $30 \%$ until $20 \mathrm{~min}$. After that, the percentage of solvent A was gradually increased from $20 \%$ to $99 \%$ in $13 \mathrm{~min}$, maintained at the same level for $9 \mathrm{~min}$, and finally decreased back to $1 \%$ in $1 \mathrm{~min}$. All of the target compounds were identified by full MS scans in positive and/or negative electrospray ionisation (ESI) mode.

\section{Results and discussion}

\subsection{Removal of selected pharmaceuticals from test solutions}

\subsubsection{Initial concentrations of $100 \mu \mathrm{g} / \mathrm{L}$}

The removal efficiencies of target compounds with initial concentrations of $100 \mu \mathrm{g} / \mathrm{L}$ by ferrate(VI) are presented in Fig. 1. Generally, the performance of ferrate(VI) varied greatly among the different target compounds. 
Fig. 1. The effect of ferrate(VI) dose and solution $\mathrm{pH}$ on the removal of pharmaceuticals from a mixed compound solution (initial concentration of $100 \mu \mathrm{g} / \mathrm{L}$ ) (a) BZF; (b) SMX; (c) DCF; and (d) CBZ.

For BZF, the removal efficiencies by ferrate(VI) under all conditions were less than $25 \%$ (Fig. 1a). The results demonstrated that raising the ferrate(VI) dose from 1 $\mathrm{mg} / \mathrm{L}$ to $5 \mathrm{mg} / \mathrm{L}$ improved the $\mathrm{BZF}$ reduction for all $\mathrm{pH}$ conditions. In terms of $\mathrm{pH}$ influence, the $\mathrm{BZF}$ removal at $\mathrm{pH} 7$ and $\mathrm{pH} 8$ was greater than that at $\mathrm{pH} 6$ and $\mathrm{pH} 9$. Specifically, the greatest BZF removal was observed at $\mathrm{pH}$ 8, where $15.3-21.4 \%$ of BZF was reduced by ferrate(VI). On the other hand, the BZF removal at $\mathrm{pH} 6$ was the lowest, with only $5.6 \%$ reduction achieved at $5 \mathrm{mg} / \mathrm{L}$ ferrate(VI).

For SMX, an increase in ferrate(VI) dose also improved the performance for all $\mathrm{pH}$ conditions (Fig. 1b). At $\mathrm{pH} \mathrm{9,} \mathrm{the} \mathrm{SMX} \mathrm{removal} \mathrm{increased} \mathrm{significantly} \mathrm{with}$ increasing ferrate(VI) dose, from $12.9 \%$ at $1 \mathrm{mg} / \mathrm{L}$ to $85.8 \%$ at $5 \mathrm{mg} / \mathrm{L}$. On the other hand, at $\mathrm{pH}$ 6-8, there was no great improvement in SMX removal with increasing ferrate(VI) dose, especially when the dose exceeded $2 \mathrm{mg} / \mathrm{L}$. However, the overall SMX removal by ferrate(VI) at $\mathrm{pH}$ 6-8 was better than that at $\mathrm{pH} 9$. Specifically, the removal percentages were all above $50 \%$ at $\mathrm{pH} 6-8$ and at the lowest dose, $1 \mathrm{mg} / \mathrm{L}$. Then, the removal of SMX gradually increased with rising ferrate(VI) dose, reaching approximately $90 \% \mathrm{SMX}$ reduction at $5 \mathrm{mg} / \mathrm{L}$.

Increasing ferrate(VI) dose improved DCF removal significantly at $\mathrm{pH}$ 6-9 (Fig. 1c). For instance, when the solution $\mathrm{pH}$ was 6, the removal of DCF by ferrate(VI) was only $4.9 \%$ at $1 \mathrm{mg} / \mathrm{L}$, and then increased with rising ferrate(VI) dose by approximately $25 \%$ for the addition of every $1 \mathrm{mg} / \mathrm{L}$ until the dose reached $4 \mathrm{mg} / \mathrm{L}$. Upon further increase in the ferrate(VI) from $4 \mathrm{mg} / \mathrm{L}$ to $5 \mathrm{mg} / \mathrm{L}$, the DCF removal rose slightly to $79 \%$. Similar patterns of DCF removal with increasing ferrate(VI) dose were also noticed at $\mathrm{pH}$ 7-9. In terms of the effect of solution $\mathrm{pH}$, at relatively high doses (4-5 mg/L), the DCF removal was not affected by the solution $\mathrm{pH}$, while at relatively low doses (1-3 mg/L), the removal efficiencies of DCF at $\mathrm{pH} 6$ were 
lower than those at $\mathrm{pH} 7-9$ by $5-20 \%$. Generally, more than $50 \%$ of DCF could be reduced in the $\mathrm{pH}$ range 6-9 when the ferrate(VI) dose reached $3 \mathrm{mg} / \mathrm{L}$.

As for $\mathrm{CBZ}$, both solution $\mathrm{pH}$ and ferrate(VI) dose exerted a significant influence on its reduction (Fig. 1d). The influence of the ferrate(VI) dose on the CBZ removal at $\mathrm{pH} 8$ and 9 was much stronger than that at $\mathrm{pH} 6$ and 7. For instance, when the solution $\mathrm{pH}$ was $9, \mathrm{CBZ}$ removal increased significantly from $23.7 \%$ at $1 \mathrm{mg} / \mathrm{L}$ to $99.1 \%$ at $5 \mathrm{mg} / \mathrm{L}$. On the other hand, at $\mathrm{pH} 6$ and 7, the CBZ reduction was increased by approximately $45 \%$ with an increase in the ferrate(VI) dose from $1 \mathrm{mg} / \mathrm{L}$ to $5 \mathrm{mg} / \mathrm{L}$. In addition, the solution $\mathrm{pH}$ significantly affected $\mathrm{CBZ}$ removal. $\mathrm{CBZ}$ removal at $\mathrm{pH}$ 8-9 was better than that at $\mathrm{pH}$ 6-7. In particular, at $\mathrm{pH} 9$, when the ferrate(VI) dose reached $4 \mathrm{mg} / \mathrm{L}$ or above, the $\mathrm{CBZ}$ reduction was higher than $90 \%$. On the other hand, the worst performance was observed at $\mathrm{pH} 6$, where the $\mathrm{CBZ}$ reduction was less than $50 \%$ for all ferrate(VI) doses.

Comparing the reduction of all four compounds, the performance of ferrate(VI) in treating BZF was the least efficient. The removal rates of the other three compounds could exceed $80 \%$ under specific conditions. Generally, a feasible operating condition was to adjust solution $\mathrm{pH}$ at 7-9 and use doses higher than $4 \mathrm{mg} / \mathrm{L}$ as Fe in applying ferrate(VI) oxidation to achieve at least 50\% of SMX, DCF and CBZ reduction from test solutions with initial concentrations of $100 \mu \mathrm{g} / \mathrm{L}$.

\subsubsection{Initial concentrations of $10 \mu \mathrm{g} / \mathrm{L}$}

The results of removing target compounds with initial concentrations of 10 $\mu \mathrm{g} / \mathrm{L}$ from test solutions by ferrate(VI) were significantly different from those obtained with an initial concentrations of $100 \mu \mathrm{g} / \mathrm{L}$, except for BZF. As shown in Fig. $2 \mathrm{a}$, the reduction of BZF was low and less than $25 \%$ under all conditions. Raising the ferrate(VI) dose slightly improved BZF removal at $\mathrm{pH} 8$ and 9. For instance, at $\mathrm{pH} 9$, the reduction of BZF by ferrate(VI) was less than $15 \%$ at ferrate(VI) doses of $1 \mathrm{mg} / \mathrm{L}$ and $2 \mathrm{mg} / \mathrm{L}$, and then slightly increased to over $20 \%$ when the ferrate(VI) dose reached $3 \mathrm{mg} / \mathrm{L}$. Additionally, at $\mathrm{pH} 7$ and 8, the removal efficiencies peaked at a ferrate(VI) dose of $3 \mathrm{mg} / \mathrm{L}$, with $11.3 \%$ and $20.6 \%$ BZF removal, respectively. 
Fig. 2. The effect of ferrate(VI) dose and solution $\mathrm{pH}$ on the removal of pharmaceuticals from a mixed compound solution (initial concentrations $10 \mu \mathrm{g} / \mathrm{L}$ ) (a) BZF; (b) SMX; (c) DCF; and (d) CBZ.

For SMX, the overall removal efficiencies by ferrate(VI) were higher than $60 \%$ for all solution $\mathrm{pH}$ and ferrate(VI) doses (Fig. 2b), with small variations for different conditions. In addition, SMX removal at $\mathrm{pH} 9$ appeared to be the best, though there was a slight drop in SMX removal when the ferrate(VI) dose was increased from 4 $\mathrm{mg} / \mathrm{L}$ to $5 \mathrm{mg} / \mathrm{L}$. For DCF, increasing the ferrate(VI) dose improved the treatment performance to some extent; however, when the solution $\mathrm{pH}$ was 6 , the removal efficiencies of DCF by ferrate(VI) remained at approximately $80 \%$ (Fig. 2c). Upon raising the ferrate(VI) dose, a significant increase in DCF removal was observed at solution $\mathrm{pH}$ 9. In terms of $\mathrm{pH}$ influence, the $\mathrm{DCF}$ removal at $\mathrm{pH}$ 6-7 appeared to be better than that at $\mathrm{pH} 8-9$, especially at ferrate(VI) doses of 2-4 mg/L. Nonetheless, the overall removal efficiency of DCF removal could exceed 50\% across the examined $\mathrm{pH}$ and dose ranges. Moreover, ferrate(VI) oxidation exhibited excellent performance for the removal of CBZ from the solution with an initial concentration of $10 \mu \mathrm{g} / \mathrm{L}$; all reduction rates were higher than 95\% (Fig. 2d).

For the removal of target compounds with initial concentrations of $10 \mu \mathrm{g} / \mathrm{L}$, CBZ removal was the highest for all operating $\mathrm{pH}$ values. On the other hand, BZF removal was the lowest at $\mathrm{pH}$ 6-9. There were no significant removal differences between DCF and SMX. For both SMX and DCF, ferrate(VI) showed good treatment performance, with removal efficiencies higher than 50\% for all applied conditions.

The results of using ferrate(VI) to treat two test solutions showed that SMX, CBZ and DCF were effectively removed at $\mathrm{pH} 6-9$; their removal efficiencies could exceed $80 \%$ under optimum conditions. However, the low removal rates of BZF suggested that ferrate(VI) is a selective oxidant. Ferrate(VI) is capable of oxidising pollutants containing ERMs [29, 30], while SMX (aniline), DCF (amine) and CBZ (olefin) all contain ERMs in their structures. On the other hand, BZF has a carboxylic 
group, which is an electron-withdrawing functional group and can depress the reactivity of aromatic rings with ferrate(VI) [21]. Thus, the low reactivity of ferrate(VI) with BZF may be attributed to the carboxylic functional group in its structure.

\subsection{Rate constants}

The rate law for the reaction of ferrate(VI) with target compounds can be written as follows:

$-d[\mathrm{Fe}(\mathrm{VI})] / d t=k_{\text {app }}[\mathrm{Fe}(\mathrm{VI})]^{\mathrm{m}}[\mathrm{X}]^{\mathrm{n}}$

Where $[\mathrm{Fe}(\mathrm{VI})]$ and $[\mathrm{X}]$ are the total molar concentrations of all species of ferrate(VI) and the target compounds, respectively; $k_{a p p}$ is the apparent rate constant of the reaction between ferrate(VI) and the target compounds; $m$ and $n$ are the orders of the reactions with respect to each reactant. Under pseudo-first-order conditions, Eq. (1) can be re-written as follows:

$-d[\mathrm{Fe}(\mathrm{VI})] / d t=k^{\prime}[\mathrm{Fe}(\mathrm{VI})]^{\mathrm{m}}$

Where $k^{\prime}=k_{\text {app }}[\mathrm{X}]^{\mathrm{n}}$.

Rate constants for the reactions of ferrate(VI) with selected pharmaceuticals were determined under pseudo-first-order conditions at $\mathrm{pH} 8.0$ and 9.0 at $20{ }^{\circ} \mathrm{C}$. The concentrations of the target compounds were at least ten times higher than that ferrate(VI). Thus, the reaction could be regarded as first-order with respect to $[\mathrm{Fe}(\mathrm{VI})]$. The experimental results also confirmed this first-order relationship with respect to $[\mathrm{Fe}(\mathrm{VI})]$. Taking the reaction of ferrate(VI) with SMX as an example, as shown in Fig. S1 of SM, the plot of ferrate(VI) degradation versus reaction time fitted nicely to a single exponential decay curve with a good coefficient of correlation (0.994), which suggests that the reaction is first-order with respect to [Fe(VI)] [31]. In this case, $m=1$ and Eq. (2) could be re-written as 
Pseudo-first-order rate constants $\left(k^{\prime}\right)$ were determined for different concentrations of the target compounds. In addition, the $k$ ' values were corrected for the ferrate(VI) self-decay rate in buffered solutions under the same $\mathrm{pH}$ condition (Text S2 and Table S2, SM). Again using SMX as an example (Fig. S2, SM), the $k$ 'values obtained at different concentrations of SMX showed a linear relationship to [SMX], which indicates that the reaction between ferrate(VI) and SMX is also first-order with respect to the concentration of SMX, and therefore $n=1$. Then, the overall reaction can thus be written as

$-d[\mathrm{Fe}(\mathrm{VI})] / d t=k_{a p p}[\mathrm{Fe}(\mathrm{VI})][\mathrm{X}]$

The apparent second-order rate constant $\left(k_{a p p}\right)$ for the reaction was then determined as the slope of the plot $k$ ' versus [SMX]. The $k_{\text {app }}$ values of the reactions for ferrate(VI) with other target compounds were determined by following the same procedure mentioned above with respect to SMX and are summarised in Table 1.

\section{Table 1}

Apparent second-order rate constants for the reactions of ferrate(VI) with selected pharmaceuticals.

Ferrate(VI) showed different reactivity with the four target compounds. Ferrate(VI) demonstrated moderate reactivity with SMX, CBZ and DCF at $\mathrm{pH}$ 9, with $k_{a p p}$ values of $1.26 \pm 0.02,1.09 \pm 0.11$ and $0.60 \pm 0.01 \mathrm{M}^{-1} \mathrm{~s}^{-1}$, respectively. Lowering the solution $\mathrm{pH}$ improved their reactivity with ferrate(VI), especially for SMX, whose $k_{a p p}$ was increased to $360 \pm 17 \mathrm{M}^{-1} \mathrm{~s}^{-1}$ at $\mathrm{pH}$ 8. This phenomenon was in agreement with many other studies $[32,33]$, which could be explained by considering the acidbase species of ferrate(VI), as given below [34]: 


$$
\begin{array}{ll}
\mathrm{H}_{3} \mathrm{FeO}_{4}{ }^{+} \leftrightarrow \mathrm{H}^{+}+\mathrm{H}_{2} \mathrm{FeO}_{4} & p K_{a l}=1.6 \\
\mathrm{H}_{2} \mathrm{FeO}_{4} \leftrightarrow \mathrm{H}^{+}+\mathrm{HFeO}_{4}{ }^{-} & p K_{a 2}=3.5 \\
\mathrm{HFeO}_{4}{ }^{-} \leftrightarrow \mathrm{H}^{+}+\mathrm{FeO}_{4}{ }^{2-} & p K_{a 3}=7.3
\end{array}
$$

Among all of the species of ferrate(VI), $\mathrm{HFeO}_{4}{ }^{-}$has been regarded as the most reactive species in many reactions $[31,35]$. Thus, with the increase of the fraction of $\mathrm{HFeO}_{4}{ }^{-}$from $\mathrm{pH} 9$ to $\mathrm{pH} 8$, the reactivity of ferrate(VI) with the target compounds improved.

On the other hand, the reactivity of ferrate(VI) with BZF was very low. The $k$ ' values of $\mathrm{BZF}$ at $\mathrm{pH} 8$ and $\mathrm{pH} 9$ were very close to the self-degradation rates of ferrate(VI) in $2 \%$ acetonitrile solution; the $k_{a p p}$ values were estimated to be less than 0.5 and $0.05 \mathrm{M}^{-1} \mathrm{~s}^{-1}$, respectively.

\subsection{Identification of oxidation products}

The test solution samples of each compound were treated by ferrate(VI) at two doses, and then analysed by LC-MS in ESI positive and/or negative mode under full MS scans. By comparing the total ion chromatograms (TICs) of the treated samples with the TICs of two blanks (ferrate(VI) and pharmaceuticals), any new peaks visible in the TICs of treated samples were then investigated further for OP identifications.

The removal rates of target compounds by ferrate(VI) varied among the four compounds (Table S3, SM). It is worth noting that the removal of BZF by ferrate(VI) was very low (2-3\%) and no OPs were found in the treated solutions. However, in treating test solution samples with initial concentrations of $10-100 \mu \mathrm{g} / \mathrm{L}$, up to $20 \%$ of BZF could be removed by $5 \mathrm{mg} / \mathrm{L}$ ferrate(VI). The extremely low removal rates of BZF obtained in this section might be explained by the following: 1) the minimal removal of BZF by ferrate(VI) was very likely attributed to the coagulation effect of ferric ions reduced from ferrate(VI); and 2) the test solutions in this section were stirred at $200 \mathrm{rpm}$ constantly, which was not ideal for the formation and aggregation of flocs and hence reduced the coagulation effect substantially.

A number of OPs were detected for SMX, DCF and CBZ in their specific test 
solutions. Most of the OPs for each compound were detected under both ferrate(VI) dose conditions. Moreover, the MS instrumental response for most of the detectable products at $10 \mathrm{mg} / \mathrm{L}$ ferrate(VI) was stronger than that at $5 \mathrm{mg} / \mathrm{L}$ (Table $\mathrm{S} 4, \mathrm{SM}$ ), which further indicated that they were the OPs resulting from ferrate(VI) oxidation. Based on the measured $\mathrm{m} / \mathrm{z}$ values, the best-fit chemical structures of such OPs were tentatively proposed by referring to prior knowledge, considering the molecular pattern of the target compounds and the mechanism of ferrate(VI) oxidation. Ferrate(VI) oxidation of organic compounds occurs via one/two-electron transfer, hydrogen abstraction or oxygen transfer [36], with great reactivity with electron-rich moieties such as olefins, phenols and amines [26].

\subsubsection{SMX}

The analysis of SMX samples was conducted in ESI positive mode in the LCMS. Three OPs of SMX with $\mathrm{m} / \mathrm{z} 269.8,267.8$ and 283.8 were found from the TIC chromatograms. SMX contains an aniline functional group and a five-member heterocyclic functional group, which are connected by a sulfonyl functional group at both sides. Both the aniline group and the heterocyclic group could be the attacking positions during ferrate(VI) oxidation [32]. The OPs of SMX with their probable structures are given in Table 2. The MW of SMX is 253; the increase of 16 atomic mass units (amu) in SMX-1 might be caused by a hydroxylation in the aniline ring of SMX [37]. Moreover, the replacement of amino group by an $\mathrm{N}=\mathrm{O}$ bond yielded SMX-2 [38]. In addition, there were two probable isobaric compounds for the SMX OP with an m/z value of 283.8, shown as the OPs SMX-3a and SMX-3b [37].

\section{Table 2}

OPs of SMX detected by LC-MS in positive mode.

The pathways of SMX's transformation during ferrate(VI) oxidation are presented in Fig. 3. The insertion of one oxygen atom resulted in the hydroxylation of the aromatic ring (SMX-1), though the precise position of the hydroxyl group could 
not be determined. The attack of ferrate(VI) might occur at the amino-N by hydrogen abstraction and oxygen insertion, yielding a nitroso-benzene derivative of SMX (SMX-2). The formation of nitroso OPs was also reported in the treatment of other sulfamide antibiotics by ferrate(VI) [17]. Further hydroxylation of the aromatic ring in SMX-2 could take place, which may have led to the formation of SMX-3a. In addition, the amino moiety might also be oxidised into a nitrobenzene derivative of SMX via oxygen transfer (SMX-3b). The formation of nitrobenzene derivatives via oxygen transfer is a common pathway for the transformation of anilines [39].

Fig. 3. Pathways of SMX degradation by ferrate(VI).

\subsection{2. $D C F$}

The concentration of DCF could be reduced to less than its limit of detection (LOD) in LC-MS when the applied ferrate(VI) was $10 \mathrm{mg} / \mathrm{L}$. Four OPs of DCF were found in the solutions treated by ferrate(VI). Specifically, two OPs were found in ESI negative mode with $\mathrm{m} / \mathrm{z}$ values of 284.1 and 279.8 , while another two OPs were detected in ESI positive mode with $\mathrm{m} / \mathrm{z}$ values of 152.1 and 309.7. Probable chemical structures were proposed in Table 3 for these OPs of DCF based on the literature [e.g., 40]. Specifically, DCF-1 was a mono-aromatic product, DCF-2 was an imino-quinone derivative of DCF, and DCF-3 was also an imino-quinone derivative with decarboxylation of the lateral chain. On the other hand, DCF-4 was formed by dihydroxylation of both aromatic rings with the lateral chain also replaced by a hydroxyl group.

\section{Table 3}

OPs of DCF detected by LC-MS in ESI positive and negative modes.

The proposed pathways of DCF during ferrate(VI) treatment are given in Fig. 4. DCF-1 is a mono-aromatic compound that was formed by the cleavage of the N-C 
bond between two aromatic rings. A N-C breakage was also observed in the oxidation of glycine by ferrate(VI) [41]. The formation of DCF-2 might occur via a major DCF intermediate, 5-hydroxy-DCF, which is commonly generated during oxidation [40]. The $-\mathrm{OH}$ and $-\mathrm{NH}_{2}$ groups in the aromatic ring of 5-hydroxy-DCF are electrondonating groups, which increased the electron density in the ortho- and para- positions of the aromatic ring and therefore attracted ferrate(VI)'s attacks on such groups and formed the keto-derivative DCF-2 via hydrogen abstraction. Hydrogen abstraction is considered to be the pathway for the oxidation of aqueous phenol to quinone by ferrate(VI) [42]. The carboxyl group of DCF-2 could be further oxidised with the loss of a $\mathrm{C}=\mathrm{O}$ carbonyl group, yielding another $\mathrm{OP}, \mathrm{DCF}-3$. Moreover, the hydroxylation on both aromatic rings of DCF and the loss of a $\mathrm{C}_{2} \mathrm{H}_{2} \mathrm{O}$ group led to the formation of DCF-4. However, based on the available information, it was not possible to determine the precise positions on the aromatic rings where the hydroxylation occurred.

Fig. 4. Pathways of DCF degradation by ferrate(VI).

\subsection{3. $C B Z$}

The CBZ molecule contains an olefinic double bond, which is an electron-rich moiety and has been reported as the main attacking site during chemical oxidation processes [43]. In the test solution samples analysed by LC-MS in positive mode, 39\% of CBZ was reduced by $10 \mathrm{mg} / \mathrm{L}$ ferrate(VI), and three OPs of CBZ with $\mathrm{m} / \mathrm{z}$ values 252.7, 266.7 and 250.8 were detected. The probable molecular formulas and chemical structures of these three OPs are presented in Table 4, by considering previous knowledge of CBZ degradation [44]. CBZ-1 had a nominal MW of 252, and the addition of $16 \mathrm{amu}$ from CBZ was equivalent to the addition of one oxygen atom. The proposed structure of CBZ-1 was 10, 11-epoxy-CBZ, which is also a major metabolite of CBZ during bio-degradation [45]. There were two probable structures for the second OP with an $\mathrm{m} / \mathrm{z}$ value of 266.7 , marked as CBZ-2a and CBZ-2b. These two products appeared to result from the opening and subsequent re-organisation of the 
heterocyclic ring. The formation of CBZ-3 also appeared to involve a series of reorganisations of the heterocyclic ring.

\section{Table 4}

OPs of CBZ detected by LC-MS in ESI positive mode.

The pathways of CBZ degradation during ferrate(VI) treatment are proposed in Fig. 5. Ferrate(VI) attacked the olefinic moiety on the central heterocyclic ring, resulting in the insertion of an oxygen atom and the formation of an epoxy derivative, CBZ-1. Further reactions of ferrate(VI) with the epoxy moiety led to the opening of the heterocyclic ring and produced a hypothesised intermediate with aldehyde and carboxyl moieties. This intermediate during CBZ degradation has also been proposed elsewhere [43]. Then, the amine moiety of the urea group $\left(-\mathrm{RR}^{\prime} \mathrm{NCONH}_{2}\right)$ in the intermediate reacted with either the carboxyl or the aldehyde moiety, which led to the formation of intra-molecular cyclisation products: CBZ-2a and CBZ-2b, respectively. The proposed degradation scheme of CBZ by ferrate(VI) is in agreement with the results of another study [46]. Moreover, the further loss of an oxygen atom from CBZ-2a yielded CBZ-3.

Fig. 5. Pathways of CBZ degradation by ferrate(VI).

\section{Conclusions}

The results of the treatment of selected pharmaceuticals in test solution samples demonstrated that ferrate(VI) can effectively remove SMX, DCF and CBZ at a ferrate(VI) dose of $3 \mathrm{mg} / \mathrm{L}$. In contrast, the removal of BZF by ferrate(VI) was less than $25 \%$ under the applied experimental conditions. Generally, increasing the dose of ferrate(VI) improved the treatment performance, while the influence of the solution $\mathrm{pH}$ on ferrate(VI) performance varied among different target compounds. 
The apparent second-order rate constants of ferrate(VI) with SMX, DCF and $\mathrm{CBZ}$ at $\mathrm{pH} 8$ and $\mathrm{pH} 9$ were established at $20^{\circ} \mathrm{C}$; the rate constants at $\mathrm{pH} 8$ (e.g., $k_{S M X}$ $=360 \pm 17 \mathrm{M}^{-1} \mathrm{~s}^{-1}$ ) were higher than that at $\mathrm{pH} 9$ (e.g., $k_{S M X}=1.26 \pm 0.02 \mathrm{M}^{-1} \mathrm{~s}^{-1}$ ). Being consistent with relatively poor BZF removal, the apparent second-order rate constants of ferrate(VI) with BZF were less than $0.5 \mathrm{M}^{-1} \mathrm{~s}^{-1}$ at $\mathrm{pH} 8$ and $\mathrm{pH} 9$. Moreover, a number of oxidation products (OPs) of SMX, DCF and CBZ during ferrate(VI) oxidation were detected, and their degradation pathways were tentatively proposed. However, no OPs of BZF were detected due to poor degradation by the ferrate(VI) oxidation.

\section{Acknowledgments}

Authors thank the Glasgow Caledonian University for offering the $\mathrm{PhD}$ studentship to Zhengwei Zhou. They are also highly grateful to Joanne Roberts, who analysed some samples to assist to identify the oxidation products. Partial support gained from the PILLS project under the EU INTERREG IVb NWE Scheme is acknowledged.

\section{Supplementary information}

Supplementary information associated with this article is attached.

\section{References}

[1] J.-Q. Jiang, Z. Zhou, V.K. Sharma, Microchem. J. 110 (2013) 292-300.

[2] R.P. Schwarzenbach, B.I. Escher, K. Fenner, T.B. Hofstetter, C.A. Johnson, U. von Gunten, B. Wehrli, Science 313 (2006) 1072-1077.

[3] T.A. Ternes, Water Res. 32 (1998) 3245-3260.

[4] G.M. Bruce, R.C. Pleus, S.A. Snyder, Environ. Sci. Technol. 44 (2010) 5619-5626.

[5] L. Santos, A.N. Araujo, A. Fachini, A. Pena, C. Delerue-Matos, M. Montenegro, J. Hazard. Mater. 175 (2010) 45-95.

[6] N. Klamerth, S. Malato, M.I. Maldonado, A. Agura, A.R. Fernandez-Alba, 
Environ. Sci. Technol. 44 (2010) 1792-1798.

[7] F. Mendez-Arriaga, R.A. Torres-Palma, C. Petrier, S. Esplugas, J. Gimenez, C. Pulgarin, Water Res. 43 (2009) 3984-3991.

[8] C. Zwiener, F.H. Frimmel, Water Res. 34 (2000) 1881-1885.

[9] T.A. Ternes, J. Stuber, N. Herrmann, D. McDowell, A. Ried, M. Kampmann, B. Teiser, Water Res. 37 (2003) 1976-1982.

[10] T. Scheers, L. Appels, B. Dirkx, L. Jacoby, L. Van Vaeck, B. Van der Bruggen, J. Luyten, J. Degreve, J. Van Impe, R. Dewil, Desalin. Water Treat. 50 (2012) 189-197.

[11] N. Klamerth, L. Rizzo, S. Malato, M.I. Maldonado, A. Aguera, A.R. FernandezAlba, Water Res. 44 (2010) 545-554.

[12] L. Rizzo, S. Meric, M. Guida, D. Kassinos, V. Belgiorno, Water Res. 43 (2009) 4070-4078.

[13] J.-Q. Jiang, B Llyod, Water Res. 36 (2002) 1397-1408.

[14] J.-Q. Jiang, J. Hazard. Mater. 146 (2007) 617-623.

[15] J.-Q. Jiang, J. Chem. Technol. Biot. 89 (2014) 165-177.

[16] U. von Gunten, J. Hoigne, Environ. Sci. Technol. 28 (1994) 1234-1242.

[17] V.K. Sharma, S.K. Mishra, N. Nesnas, Environ. Sci. Technol. 40 (2006) 72227227.

[18] L. Hu, H.M. Martin, O. Arcs-Bulted, M.N. Sugihara, K.A. Keatlng, T.J. Strathmann, Environ. Sci. Technol. 43 (2009) 509-515.

[19] J.-Q. Jiang, Z. Zhou, O. Pahl, Sep. Purif. Technol. 88 (2012) 95-98.

[20] S.G. Zimmermann, A. Schmukat, M. Schulz, J. Benner, U. von Gunten, T.A. Ternes, Environ. Sci. Technol. 46 (2012) 876-884.

[21] B. Yang, G.-G. Ying, J.-L. Zhao, S. Liu, L.-J. Zhou, F. Chen, Water Res. 46 (2012) 2194-2204.

[22] E.M. Casbeer, V.K. Sharma, Z. Zajickova, D.D. Dionysiou, Environ. Sci. Technol. 47 (2013) 4572-4580.

[23] Y. Ma, N.Y. Gao, C. Li, Environ. Eng. Sci. 29 (2012) 357-362.

[24] D. Ashton, M. Hilton, K.V. Thomas, Sci. Total Environ. 333 (2004) 167-184.

[25] R. Rosal, A. Rodriguez, J.A. Perdigon-Melon, A. Petre, E. Garcia-Calvo, M.J. 
Gomez, A. Aguera, A.R. Fernandez-Alba, Water Res. 44 (2010) 578-588.

[26] Y. Lee, S.G. Zimmermann, A.T. Kieu, U. von Gunten, Environ. Sci. Technol. 43 (2009) 3831-3838.

[27] Y. Lee, J. Yoon, U. von Gunten, Water Res. 39 (2005) 1946-1953.

[28] Z. Zhou, J.-Q. Jiang, J. Appl. Spectroscopy 81 (2014) 278-282.

[29] J.-Q. Jiang, Z. Zhou, S. Patibandla, X. Shu, Microchem. J. 110 (2013) 239-245.

[30] V.K. Sharma, Adv. Environ. Res. 6 (2002) 143-156.

[31] V.K. Sharma, M. Sohn, G.A.K. Anquandah, N. Nesnas, Chemosphere, 87 (2012) 644-648.

[32] V.K. Sharma, S.K. Mishra, A.K. Ray, Chemosphere, 62 (2006) 128-134.

[33] B. Yang, G.-G. Ying, J.-L. Zhao, L.-J. Zhang, Y.-X. Fang, L.D. Nghiem, J. Hazard. Mater. 186 (2011) 227-235.

[34] J.D. Rush, Z.W. Zhao, B.H.J. Bielski, Free Radic. Res. 24 (1996) 187-198.

[35] V.K. Sharma, C.R. Burnett, D.B. O'Connor, D. Cabelli, Environ. Sci. Technol. 36 (2002) 4182-4186.

[36] V.K. Sharma, Environ. Sci. Technol. 44 (2010) 5148-5152.

[37] M.D. Gomez-Ramos, M. Mezcua, A. Aguera, A.R. Fernandez-Alba, S. Gonzalo, A. Rodriguez, R. Rosal, J. Hazard. Mater. 192 (2011) 18-25.

[38] M.M. Ahmed, S. Barbati, P. Doumenq, S. Chiron, Chem. Eng. J. 197 (2012) 440447.

[39] V.K. Sharma, J. Environ. Sci. Heal. A 45 (2010) 645-667.

[40] A.D. Coelho, C. Sans, A. Aguera, M.J. Gomez, S. Esplugas, M. Dezotti, Sci. Total Environ. 407 (2009) 3572-3578.

[41] N. Noorhasan, B. Patel, V.K. Sharma, Water Res. 44 (2010) 927-935.

[42] H. Huang, D. Sommerfeld, B.C. Dunn, E.M. Eyring, C.R. Lloyd, J. Phys. Chem. A 105 (2001) 3536-3541.

[43] D.C. McDowell, M.M. Huber, M. Wagner, U. von Gunten, T.A. Ternes, Environ. Sci. Technol. 39 (2005) 8014-8022.

[44] D.P. Mohapatra, S.K. Brar, R.D. Tyagi, P. Picard, R.Y. Surampalli, Sci. Total Environ. 447 (2013) 280-285. 
[45] X.-S. Miao, J.-J. Yang, C.D. Metcalfe, Environ. Sci. Technol. 39 (2005) 74697475 .

[46] L. Hu, H.M. Martin, O. Arcs-Bulted, M.N. Sugihara, K.A. Keatlng, T.J. Strathmann, Environ. Sci. Technol. 43 (2009) 509-515.
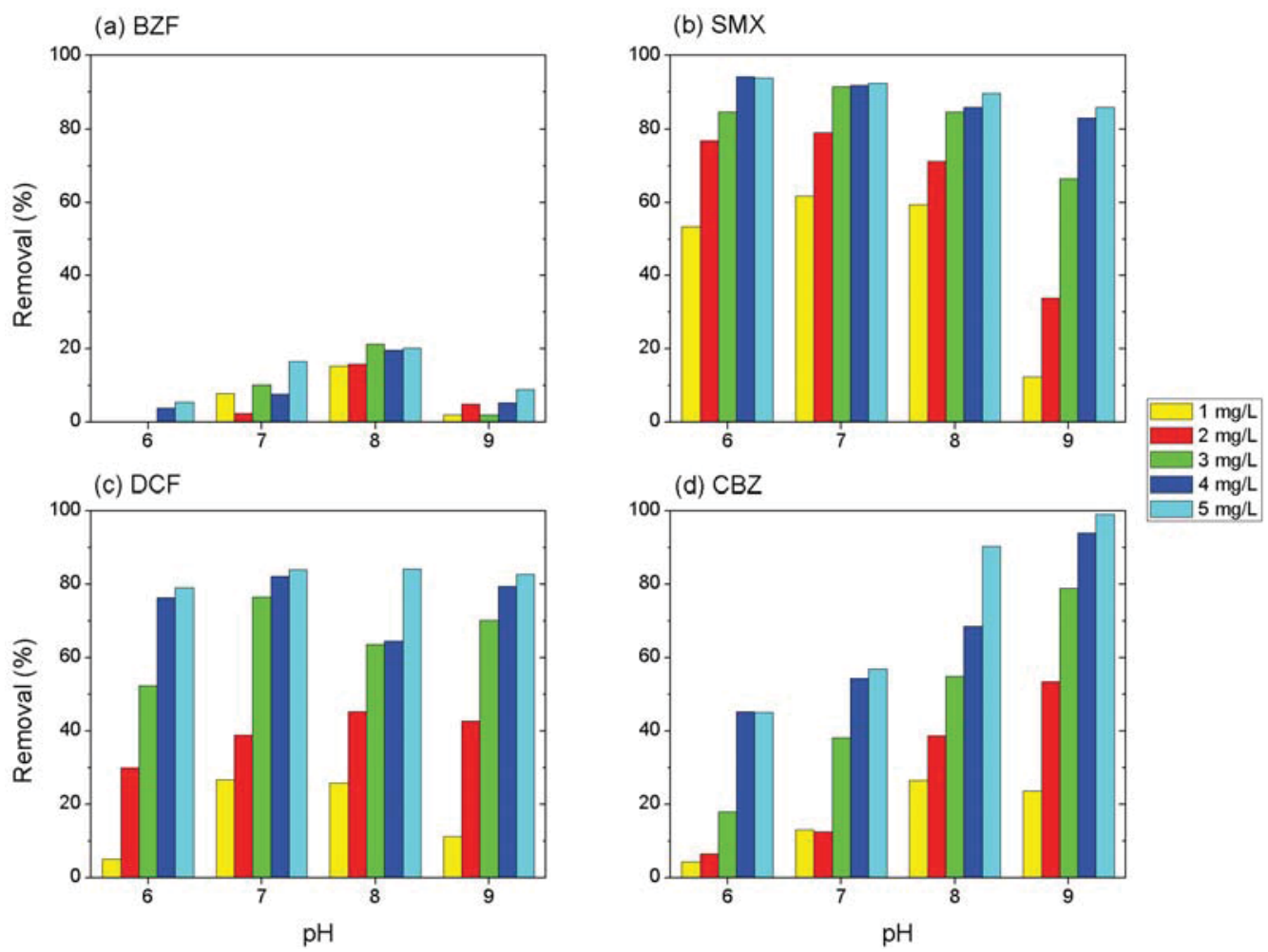

Fig. 1. The effect of ferrate(VI) dose and solution $\mathrm{pH}$ on the removal of pharmaceuticals from a mixed-compound solution (initial concentration of $100 \mu \mathrm{g} / \mathrm{L}$ ) (a) BZF; (b) SMX; (c) DCF; and (d) CBZ. 

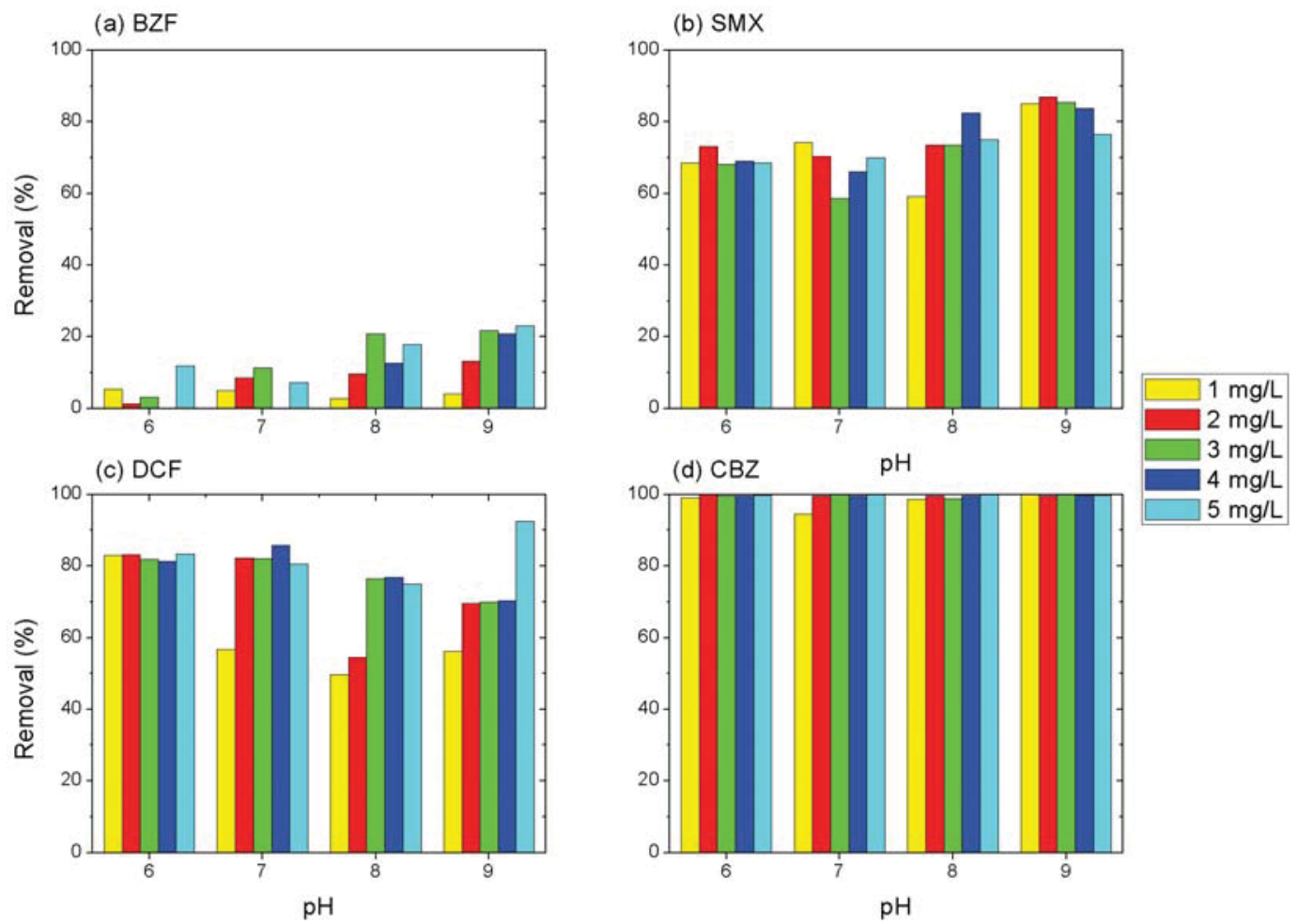

Fig. 2. The effect of ferrate(VI) dose and solution $\mathrm{pH}$ on the removal of pharmaceuticals from a mixed-compound solution (initial concentration of $10 \mu \mathrm{g} / \mathrm{L}$ ) (a) BZF; (b) SMX; (c) DCF; and (d) CBZ.
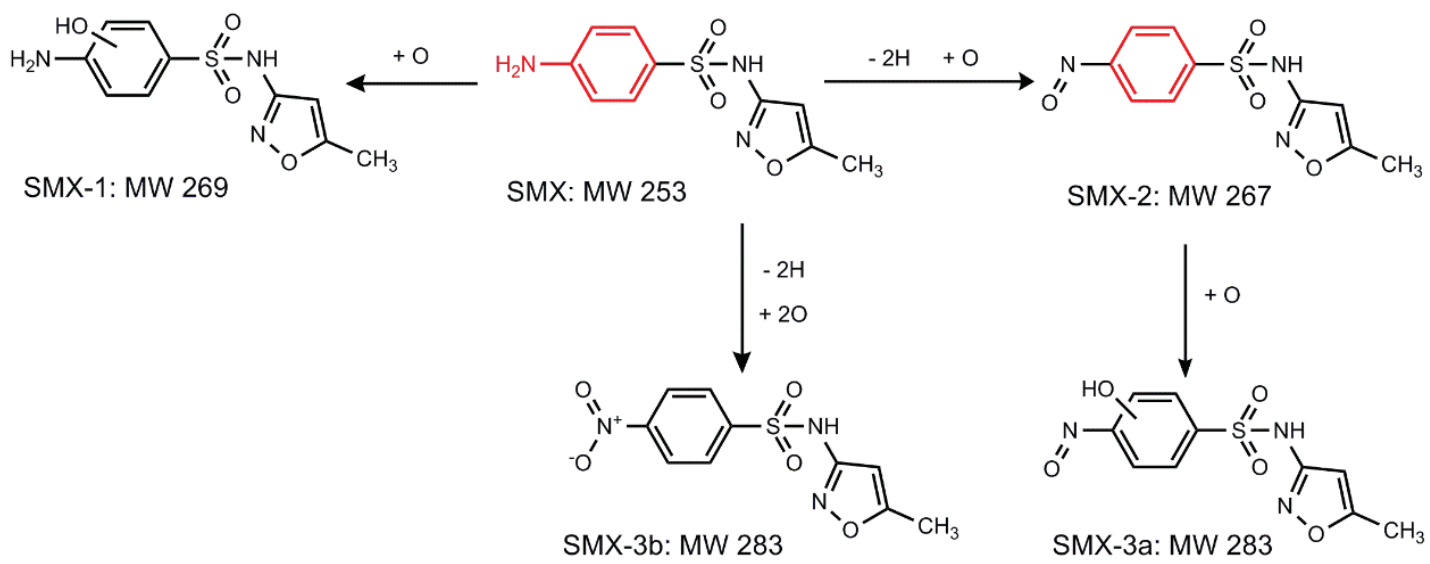

SMX-1: MW 269

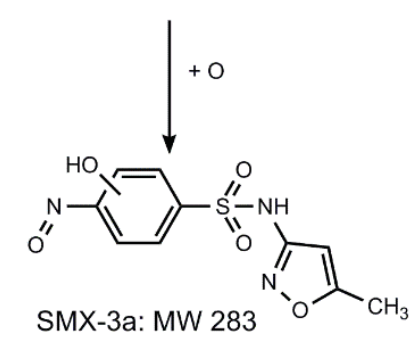

Fig. 3. Pathways of SMX degradation by ferrate(VI). 

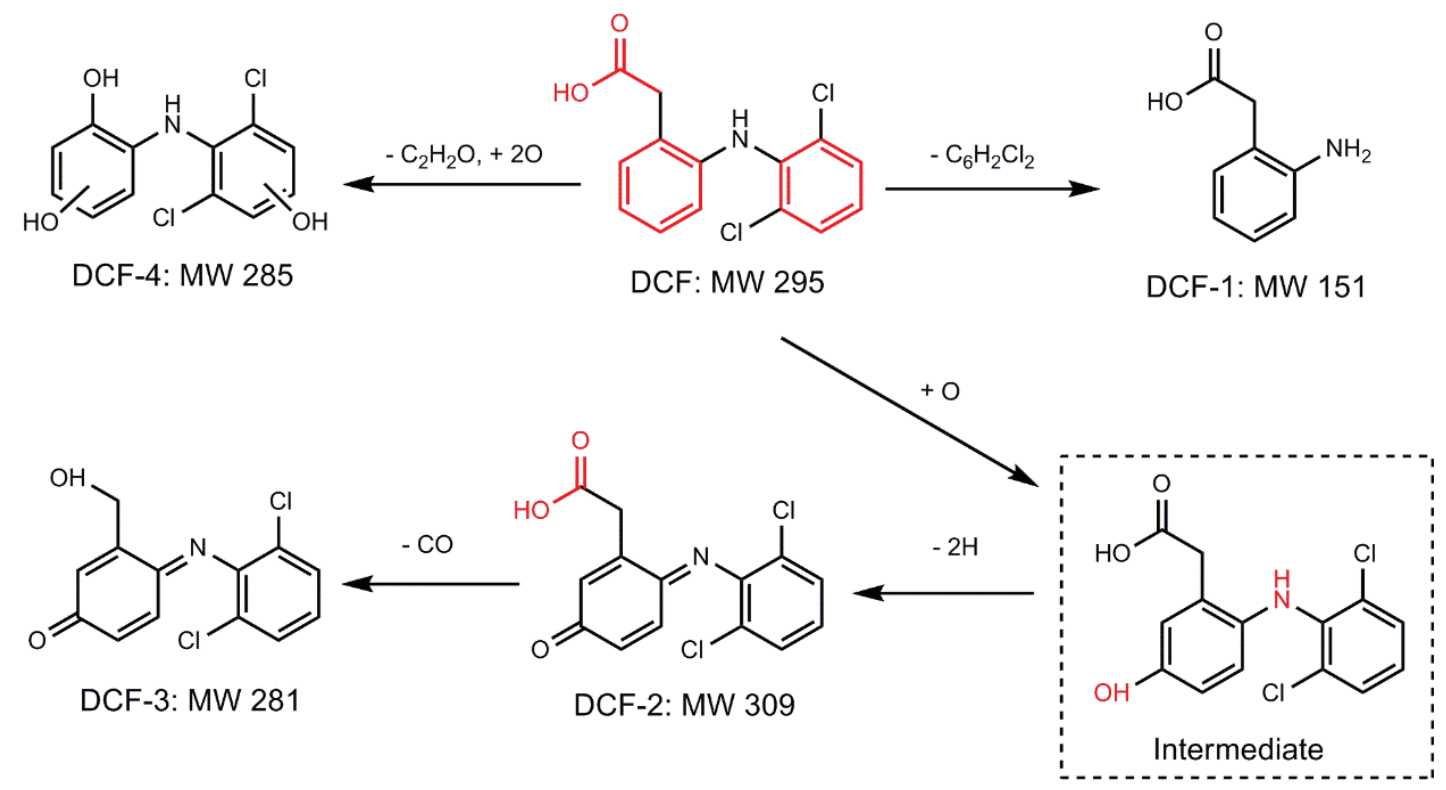

Fig. 4. Pathways of DCF degradation by ferrate(VI).<smiles>NC(=O)N1c2ccccc2C=Cc2ccccc21</smiles>

CBZ: MW 236

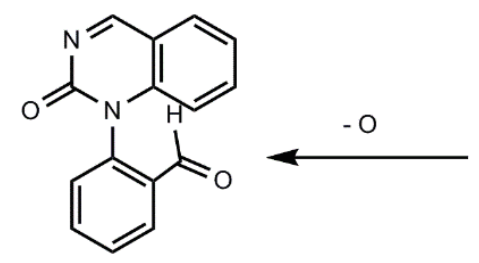

CBZ-3: MW 250<smiles>NC(=O)N1c2ccccc2C2OC2c2ccccc21</smiles>

CBZ-1: MW 252<smiles>O=c1[nH]c(=O)n(-c2ccccc2)c2ccccc12</smiles>

CBZ-2a: MW 266
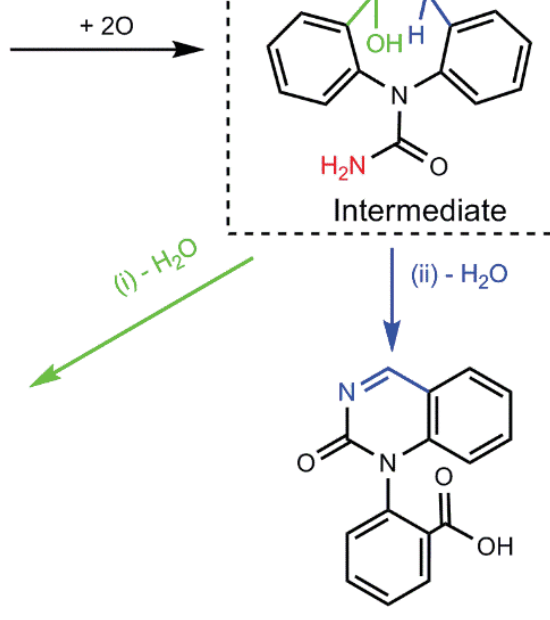

CBZ-2b: MW 266

Fig. 5. Pathways of CBZ degradation by ferrate(VI). 


\section{Table 1}

Apparent second-order rate constants for the reactions of ferrate(VI) with selected pharmaceuticals.

\begin{tabular}{ccc}
\hline Compound & \multicolumn{2}{c}{$\boldsymbol{k}_{\text {app }}\left(\mathbf{M}^{-1} \mathbf{s}^{-1}\right)$} \\
& pH 8 & pH 9 \\
\hline SMX & $360 \pm 17$ & $1.26 \pm 0.02$ \\
DCF & $12.48 \pm 0.98$ & $0.60 \pm 0.01$ \\
CBZ & $23.83 \pm 0.52$ & $1.09 \pm 0.11$ \\
BZF & $<0.5$ & $<0.05$ \\
\hline
\end{tabular}


Table 2

OPs of SMX detected by LC-MS in positive mode.

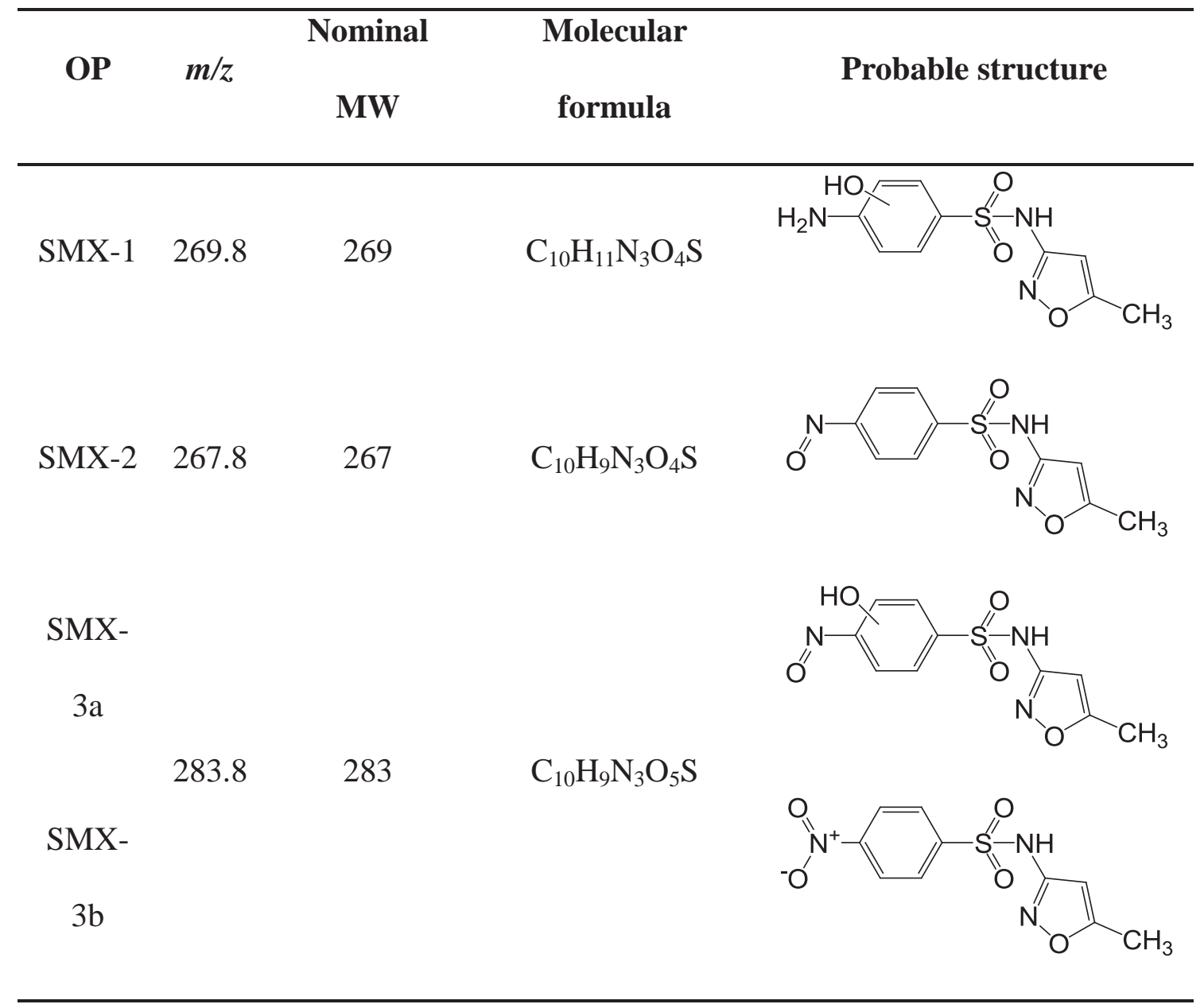


Table 3

OPs of DCF detected by LC-MS in ESI positive and negative modes.

\begin{tabular}{|c|c|c|c|c|}
\hline OP & $m / z$ & Nominal MW & Molecular formula & Probable structure \\
\hline DCF-1 & $\begin{array}{c}152.1 \\
\left([\mathrm{M}+\mathrm{H}]^{+}\right)\end{array}$ & 151 & $\mathrm{C}_{8} \mathrm{H}_{9} \mathrm{O}_{2} \mathrm{~N}$ & \\
\hline DCF-2 & $\begin{array}{c}309.7 \\
\left([\mathrm{M}+\mathrm{H}]^{+}\right)\end{array}$ & 309 & $\mathrm{C}_{14} \mathrm{H}_{9} \mathrm{NO}_{3} \mathrm{Cl}_{2}$ & \\
\hline DCF-3 & $\begin{array}{c}279.8 \\
\left([\mathrm{M}-\mathrm{H}]^{-}\right)\end{array}$ & 281 & $\mathrm{C}_{13} \mathrm{H}_{9} \mathrm{NO}_{2} \mathrm{Cl}_{2}$ & \\
\hline DCF-4 & $\begin{array}{c}284.1 \\
\left([\mathrm{M}-\mathrm{H}]^{-}\right)\end{array}$ & 285 & $\mathrm{C}_{12} \mathrm{H}_{9} \mathrm{NO}_{3} \mathrm{Cl}_{2}$ & \\
\hline
\end{tabular}


Table 4

OPs of CBZ detected by LC-MS in ESI positive mode.

\begin{tabular}{cccccc}
\hline OP & $\mathbf{m} / \mathbf{z}$ & Nominal $\mathbf{M W}$ & Molecular formula Probable structure \\
$\mathrm{CBZ}-1$ & 252.7 & 252 & $\mathrm{C}_{15} \mathrm{H}_{12} \mathrm{~N}_{2} \mathrm{O}_{2}$ & \\
$\mathrm{CBZ}-2 \mathrm{a}$ & & &
\end{tabular}

